\title{
Double outlet left ventricle
}

INSERM

\section{Source}

INSERM. (1999). Orphanet: an online rare disease and orphan drug data base. Double outlet left ventricle. ORPHA:3427

Double-outlet left ventricle (DOLV) is an extremely rare congenital cardiac malformation in which both the aorta and the pulmonary artery arise, either exclusively or predominantly, from the morphologic left ventricle. 